\title{
Biallelic Variants in LAMB1 Causing Hydranencephaly: A Severe Phenotype of a Rare Malformative Encephalopathy
}

\author{
Kuntal Sen, MD ${ }^{10}$ Shagun Kaur, MD² David W. Stockton, MD² Mary Nyhuis, MS, CGC ${ }^{3}$ \\ Jacquelyn Roberson, $\mathrm{MD}^{3}$ \\ ${ }^{1}$ Division of Neurogenetics and Developmental Pediatrics, Children's \\ National Hospital, Washington, District of Columbia \\ 2 Division of Genetic, Genomic, and Metabolic Disorders, Children's \\ Hospital of Michigan, Detroit, Michigan \\ ${ }^{3}$ Department of Prenatal and Cancer Genetics, Henry Ford Health \\ System, Detroit, Michigan \\ Am J Perinatol Rep 2021;11:e26-e28.

\begin{abstract}
Address for correspondence Kuntal Sen, MD, Division of Neurogenetics and Developmental Pediatrics, Children's National Hospital, Washington, DC 20010-2978 (e-mail: ksen2@cnmc.org).
\end{abstract}

Abstract
Keywords
- hydranencephaly
- LAMB1
- $\alpha$-dystroglycanopathy
- whole genome
sequencing

Case Report A 32-year-old female with a history of three prior pregnancy losses presented for genetic testing following an ultrasonography diagnosis of fetal hydranencephaly. Baby was born via C-section and was noted to have a head circumference of $48 \mathrm{~cm}$, in addition to ocular and cardiac anomalies and dysmorphic features. Whole genome sequencing revealed a homozygous variant in LAMB1 gene.

Discussion The pathobiogenesis of hydranencephaly is incompletely understood and is attributed to vascular, infectious, or genetic etiology. Herein we present LAMB1 as a monogenic cause of fetal hydranencephaly which was incompatible with life. Previously, LAMB1-associated phenotype consisted of cobblestone lissencephaly and hydrocephalus, developmental delay, and seizures. Our proband expands the phenotypic spectrum of this malformative encephalopathy.
Bi-allelic variants in the LAMB1 gene have been reported to cause a neurodevelopmental disorder characterized by psychomotor delays, seizures, ocular anomalies, lissencephaly, and hydrocephalus (lissencephaly-5/LIS5, OMIM \#615191)., ${ }^{1,2}$ Mutations in this gene lead to malformations of cortical development due to aberrant connection between the pial basement membrane and glial cells. We report a case of hydranencephaly representing a more severe manifestation compared with previously known phenotype of LAMB1.

\section{Case Report}

A 32-year-old G9 Yemeni female was referred to our institution for prenatal genetic counseling following an antenatal ultraso- nography (US) concerning for hydranencephaly and polyhydramnios. Obstetric history was significant for spontaneous loss of three previous fetuses. Physical features of the fetuses and etiology for miscarriages were not ascertained. Of note, these were the products of a consanguineous union, as the patient and her husband were double first cousins. The present pregnancy was otherwise uncomplicated. Repeat US re-demonstrated hydranencephaly with a thin rim of falx cerebri in addition to identifying a ventricular septal defect (VSD) and visualization of a single ocular lens (-Fig. 1). Chromosomal microarray analysis on amniocytes revealed loss of heterozygosity in more than $20 \%$ of the genome, however, did not show any clinically significant deletions or duplications. A dystroglycanopathy gene panel and sequencing of L1CAM gene were

\footnotetext{
(C) 2021. The Author(s).

This is an open access article published by Thieme under the terms of the Creative Commons Attribution-NonDerivative-NonCommercial-License, permitting copying and reproduction so long as the original work is given appropriate credit. Contents may not be used for commercial purposes, or adapted, remixed, transformed or built upon. (https://creativecommons.org/ licenses/by-nc-nd/4.0/)

Thieme Medical Publishers, Inc., 333 Seventh Avenue, 18th Floor,
} New York, NY 10001, USA received

accepted after revision

November 6, 2020 https://doi.org/

ISSN 2157-6998. 


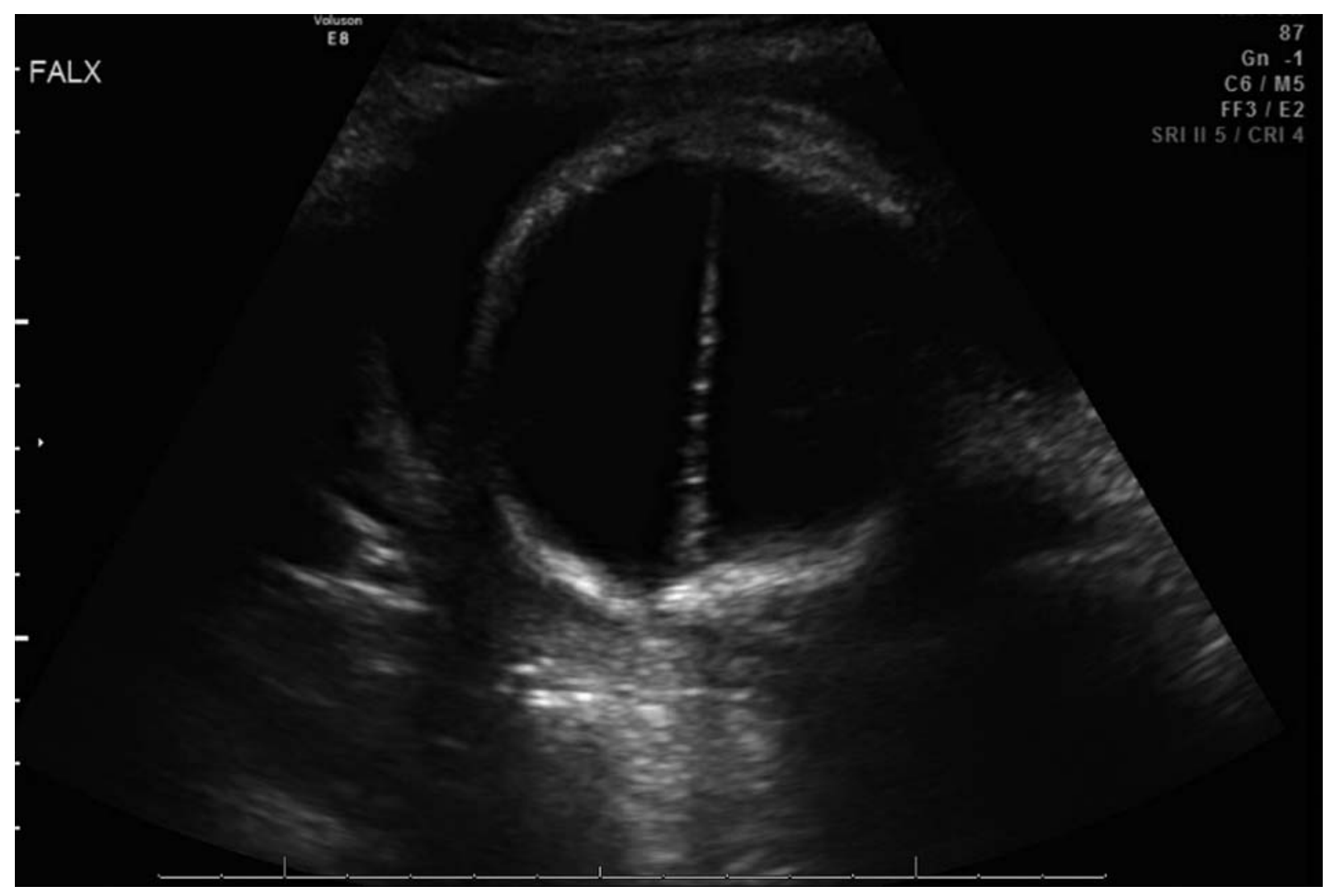

Fig. 1 Antenatal ultrasound showing gross absence of cortical matter with the exception of thin flax cerebri and replacement of cranial vault with cerebrospinal fluid.

ordered given the combination of brain and ocular malformations, but the results were nondiagnostic. Testing for congenital infections including toxoplasmosis, rubella, cytomegalovirus was negative. A fetal MRI was performed shortly before delivery which was consistent with the previously visualized anomalies. A male infant was delivered at 34 weeks and 2 days of gestational age via caesarean section due to cephalopelvic disproportion. The head circumference at birth was $48 \mathrm{~cm}$ which was greater than 99th percentile and third standard deviation for gestational age. He had poor respiratory drive at birth and needed intubation. The baby was noted to have low set, posteriorly rotated ears, brachydactyly, a sacral dimple, and cryptorchidism in addition to the antenatally diagnosed severe cortical malformations. A VSD with patent ductus arteriosus was noted on echocardiography. Ophthalmologic evaluation showed irregular oval-shaped pupils which were nonreactive. Baby was noted to have brief irregular episodes of upper and lower extremity jerking which was characterized as benign myoclonus. Post-natal course was also complicated by indirect hyperbilirubinemia. The baby could not be weaned off ventilator and given severe brain malformations which were deemed incompatible with life, life support was withdrawn. Whole genome sequencing analysis identified a homozygous variant in the LAMB1 gene [c.4859T > C, p.Ile1620Thr]. This variant is a missense change that has not been reported in population databases including Thousand Genomes and gnomAD and is predicted to be damaging based on SIFT algorithm. The parents received appropriate genetic counseling in our clinic.

\section{Discussion}

Hydranencephaly is a condition characterized by the absence of cortical mass with cerebrospinal fluid filling the intracranial space. The etiology and pathogenesis of hydranencephaly is not entirely delineated. ${ }^{3}$ It is conventionally recognized to be secondary to vasculopathy or intrauterine infections, and there are only a handful of reports regarding single gene causes of hydranencephaly. Vascular incidents in the form of malformation of internal carotid and other intracranial arteries lead to either arrest in brain development or destruction of already formed brain tissue. ${ }^{4}$ Congenital infections such as toxoplasmosis or rubella and teratogenic exposure such as cocaine or valproic acid have also been implicated. ${ }^{5}$ Syndromic or monogenic causes of hydranencephaly are not well known but there have been reports associated with mutations in the COL4A1 gene and the PI3KAkt3-mTOR pathway. ${ }^{6,7}$ We report a case of homozygous single nucleotide variants in LAMB1 gene being causative of hydranencephaly in conjunction with mild cardiac and ocular defects. LAMB1 mutations as a cause of cortical malformations were first reported in 2013, and at the time of writing there were six individuals (three families) described ( - Table 1 ). Clinical features in these patients unanimously included moderate-severe developmental delay, seizures, hydrocephalus, and a variety of ocular abnormalities ranging from optic atrophy to lens opacification. ${ }^{1,2}$ The pathognomonic neuroimaging findings were cobblestone lissencephaly and hydrocephalus, but also included other anatomic peculiarities such as cerebellar hypoplasia, 
Table 1 Phenotypic spectrum of LAMB1-related neurodevelopmental disorder

\begin{tabular}{|c|c|c|c|}
\hline & $\begin{array}{l}\text { Radmanesh et al } \\
(n=3)\end{array}$ & $\begin{array}{l}\text { Tonduti et al } \\
(n=2)\end{array}$ & Present case \\
\hline Psychomotor delays & $3 / 3$ & $2 / 2$ & $\mathrm{~N} / \mathrm{A}$ \\
\hline $\begin{array}{l}\text { Seizures and } \\
\text { infantile spasms }\end{array}$ & $0 / 3$ & $2 / 3$ & $?$ \\
\hline Ocular abnormalities & $0 / 3$ & $\begin{array}{l}\text { Optic atrophy, } \\
\text { lens opacities }\end{array}$ & Irregular nonreactive pupils \\
\hline $\begin{array}{l}\text { Age at the time } \\
\text { of reporting }\end{array}$ & $?$ & 34 y & Passed away in first month of life \\
\hline Brain anomalies & $\begin{array}{l}\text { Cobblestone } \\
\text { lissencephaly, } \\
\text { hydrocephalus }\end{array}$ & $\begin{array}{l}\text { Agyria/lissencephaly, } \\
\text { hydrocephalus, white } \\
\text { matter abnormalities }\end{array}$ & Hydranencephaly with thin falx cerebri \\
\hline
\end{tabular}

temporal lobe cysts, and white matter abnormalities. ${ }^{1,2}$ Although there was significant clinical overlap in our patient, the previous cases were diagnosed later in childhood or in adolescence, and MRI findings were less dramatic. Therefore, our proband possibly represents the most severe phenotype due to $L A M B 1$ reported to date. The sibship reported by Tonduti et al lived up to at least third decade of lives but with progressively worsening neurological symptoms. For our patient, the possibility of multiple autosomal recessive conditions was raised given extensive loss of heterozygosity, however, whole genome sequencing did not reveal pathogenic or likely pathogenic variants in any genes associated with the phenotype. $L A M B 1$ codes for subunit $\beta 1$ of laminin, is a crucial component of the basal laminae, and helps to regulate the differentiation and migration of neuronal cells. ${ }^{1}$ LAMB1-associated malformative encephalopathy should be considered as a differential diagnosis for muscle-eye-brain disease ( $\alpha$-dystroglycanopathies) and COL4A1-related porencephaly. This is propounded by shared clinical features (severe cortical malformation and eye abnormalities) as well as our understanding of the molecular mechanisms.

\section{Conclusion}

This report contributes to the scarce number of known monogenic causes of hydranencephaly while expanding the phenotypic spectrum of LAMB1-related neurological disorder. It also adds to the list of differential diagnoses that must be considered in a patient presenting with a conjunction of brain and eye abnormalities.

\section{Conflict of Interest}

None declared.

\section{References}

1 Radmanesh F, Caglayan AO, Silhavy JL, et al. Mutations in LAMB1 cause cobblestone brain malformation without muscular or ocular abnormalities. Am J Hum Genet 2013;92(03):468-474

2 Tonduti D, Dorboz I, Renaldo F, et al. Cystic leukoencephalopathy with cortical dysplasia related to LAMB1 mutations. Neurology 2015;84(21):2195-2197

3 Pavone P, Praticò AD, Vitaliti G, et al. Hydranencephaly: cerebral spinal fluid instead of cerebral mantles. Ital J Pediatr 2014; 40:79

4 Quek YW, Su PH, Tsao TF, et al. Hydranencephaly associated with interruption of bilateral internal carotid arteries. Pediatr Neonatol 2008;49(02):43-47

5 Cecchetto G, Milanese L, Giordano R, Viero A, Suma V, Manara R. Looking at the missing brain: hydranencephaly case series and literature review. Pediatr Neurol 2013;48(02):152-158

6 Meuwissen ME, de Vries LS, Verbeek HA, et al. Sporadic COL4A1 mutations with extensive prenatal porencephaly resembling hydranencephaly. Neurology 2011;76(09):844-846

7 Rivière JB, Mirzaa GM, O'Roak BJ, et al;Finding of Rare Disease Genes (FORGE) Canada Consortium. De novo germline and postzygotic mutations in AKT3, PIK3R2 and PIK3CA cause a spectrum of related megalencephaly syndromes. Nat Genet 2012;44(08): 934-940 